\title{
Thiamine Response in Maple Syrup Urine Disease
}

\author{
PAUL M. FERNHOFF, DEBORAH LUBITZ, DEAN J. DANNER, PHILLIP P. DEMBURE, \\ HANS P. SCHWARTZ, RICHARD HILLMAN, DENNIS M. BIER, AND LOUIS J. ELSAS \\ Division of Medical Genetics, Department of Pediatrics [P.M.F., D.L., D.J.D., P.P.D., L.J.E.], Emory University \\ School of Medicine, Atlanta, Georgia 30322, and Department of Pediatrics, Metabolism Division [H.P.S., R.H., \\ D.M.B.J, Washington University, School of Medicine, St. Louis, Missouri 63110
}

\begin{abstract}
We measured the biochemical response for four patients with maple syrup disease to pharmacologic doses of thiamine, and correlated their response to their branched chain $\alpha$-ketoacid dehydrogenase activity. We observed a linear correlation between the concentrations of each plasma branched-chain amino acid and its corresponding ketoacid analogue. In addition, the renal tubular reabsorption of branched-chain amino and ketoacids was nearly complete within these physiologic concentrations. Three children responded to thiamine therapy with a reduction in concentration of plasma and urinary branched-chain amino and ketoacids. Each responder had at least $5 \%$ activity for branched chain $\alpha$-ketoacid dehydrogenase in their mononuclear blood cells and in whole cell fibroblasts from cultured skin when compared to the activity in normal control cells. We propose that each child with maple syrup urine disease be assessed for their response to thiamine by quantifying the concentration of branched-chain amino acids in plasma before and after vitamin supplementation. (Pediatr Res 19: 1011-1016, 1985)
\end{abstract}

\section{Abbreviations}

BCKA, Branched-chain $\alpha$-ketoacidemia

MSUD, Maple syrup urine disease

BCAA, branched chain amino acids

BCKA, branched chain $\alpha$-ketoacids

BCKAD, branched chain $\alpha$-ketoacid dehydrogenase

KIC, $\alpha$-ketoisocaproic acid

KMV, $\alpha$-keto- $\rho$-methylvaleric acid

KIV, $\alpha$-ketoisovaleric acid

More than 25 yr ago, Menkes et al. (1) described four siblings with progressive neurologic disorders and sugary-smelling urine. The fragrant urinary compounds have since been identified as BCKA which accumulated as the result of impairment in the mitochondrial enzyme complex, BCKAD (E.C. 1.2.4.1.). All three BCKA accumulated: KIC; $\operatorname{KVM}$; and $\operatorname{KIV}(2,3)$. In patients with MSUD, BCKA results from this impaired catabolic pathway. By restricting dietary BCAA early in infancy, the clinical manifestations of MSUD can be ameliorated or prevented $(4,5)$.

Several patients have been reported with thiamine responsive

Received December 24, 1984; accepted May 20, 1985.

Reprint requests Paul M. Fernhoff, M.D., Division of Medical Genetics, Department of Pediatrics, Emory University School of Medicine, 2040 Ridgewood Drive, N.E., Atlanta, GA 30322.

Supported by USPHS grants from NIH HD-10667, NIH HD-08388 and CRC 00039 . forms of MSUD (6-10). Elsas et al. (8) described the responses of two brothers with MSUD to increasing oral doses of thiamine. While taking $150 \mathrm{mg} /$ day of thiamine, the brothers decreased their urinary excretion of BCKA and had increased activity of $\mathrm{BCKAD}$ as measured in peripheral blood lymphocytes. Based on these and additional in vivo and in vitro studies, Danner and coworkers $(7,8,11-13)$ proposed that after its conversion to intracellular thiamine pyrophosphate, binding of this active cofactor to the multienzyme complex induced a conformational change which stabilized normal and mutant enzyme. This conformational change decreased the rate of biologic degradation of the complex and over time, increased overall enzyme activity (7, $8,11-13)$.

Because of differences in reported doses and rapidity with which thiamine altered the patient's sensitivity to protein, it has remained unclear which patients would respond and which analysis could predict the response to thiamine therapy. The present study controlled for several variables, including the dietary intake of BCAA and the dose of thiamine. Plasma concentrations and renal transport of BCAA and BCKA were compared in four children affected with MSUD to determine whether pharmacologic doses of thiamine affect renal clearance of BCAA and BCKA. Each patient's biochemical response was correlated with residual activity of $\mathrm{BCKAD}$ in freshly isolated blood mononuclear cells and in their cultured skin fibroblasts.

\section{METHODS}

Clinical protocol. Four patients (Table 1), whose parents gave their informed consent, were studied.

J.P., a 17-month-old black male, was diagnosed at 13 days of age. His developmental landmarks were moderately delayed.

T.Mc., a 24/12-yr-old white female, was diagnosed at 19 days of age. Despite normal development, she had recurrent bouts of otitis, seizures, and ataxia.

C.M., a 31/12-yr-old white female, was treated from 14 days of age. She had previous episodes of ketoacidosis and seizures. Her development was moderately delayed.

V.H., a $91 / 2$-yr-old-white male was diagnosed at 2 yr. His development was delayed, but he never developed ketoacidosis. He was the only child in this study whose diet was restricted in protein without specific restriction of the BCAA. He had taken thiamine ( $100 \mathrm{mg} /$ day) for $7 \mathrm{yr}$ before discontinuing one month prior to this study.

Before and during the study patients were fed a diet restricted in BCAA determined as optimal by the referring metabolic center. Patients were admitted to the Emory University Clinical Research Facility for 2 days of diet equilibration followed by 1 wk of baseline studies. These included three plasma samples after overnight fasting and three 24-h urine collections for quantitation of amino acids and organic acids. Mononuclear cells were iso- 
Table 1. Clinical profile of patients

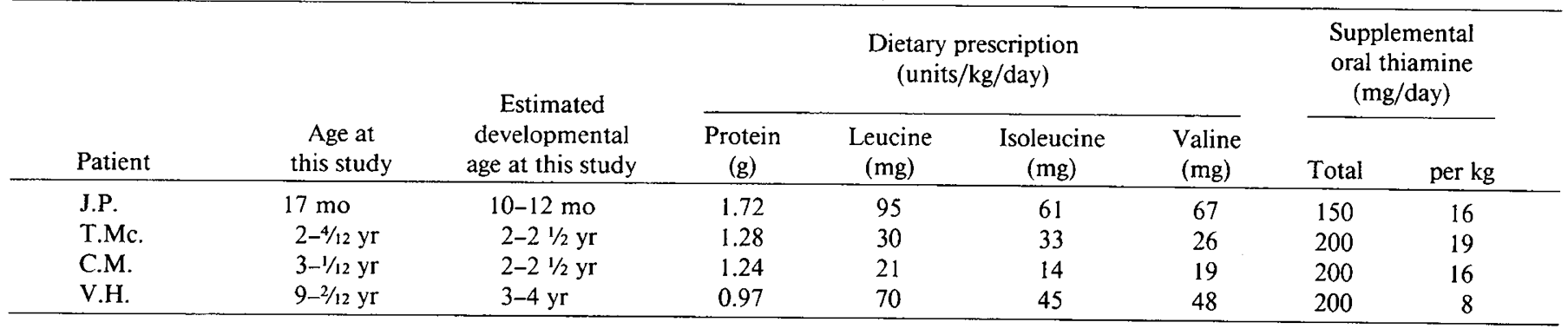

Table 2. Effect of thiamine on fasting plasma branched chain amino acid concentration

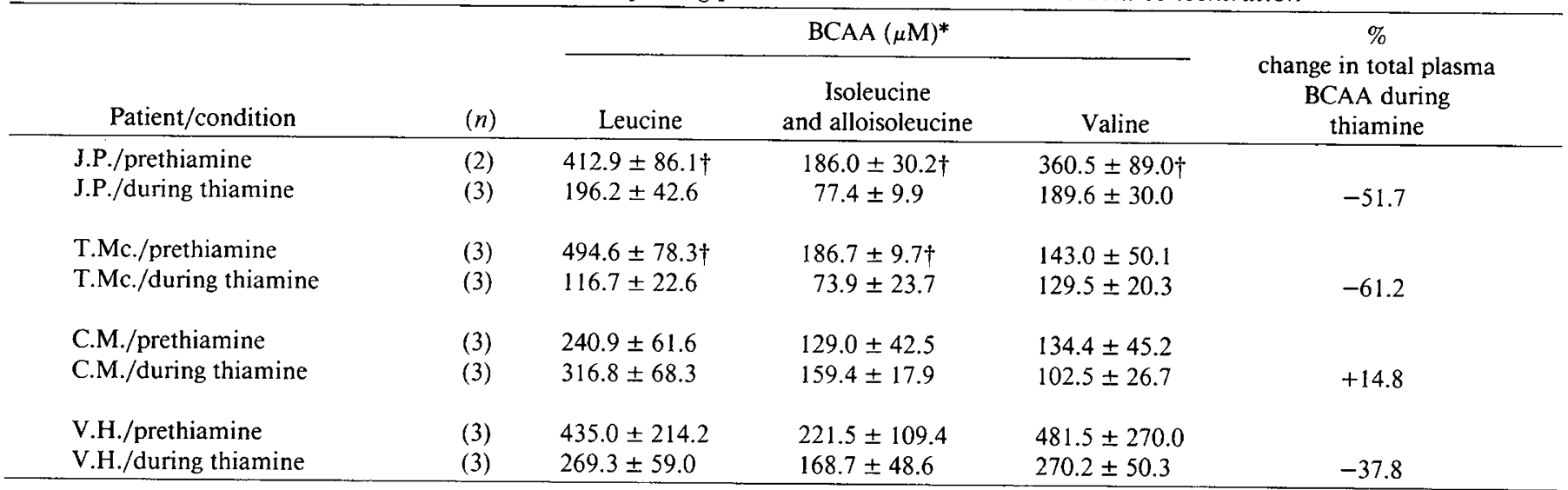

* Plasma concentration is the mean $\pm 1 \mathrm{SD}$. When only two samples were available, concentration is the average and range.

$\dagger$ Plasma aminoacid concentration was significantly less during thiamine therapy with $p<0.05$ using a one-tailed $t$ test for independent mean probability.

Table 3. Effect of thiamine on fasting plasma BCKA concentration

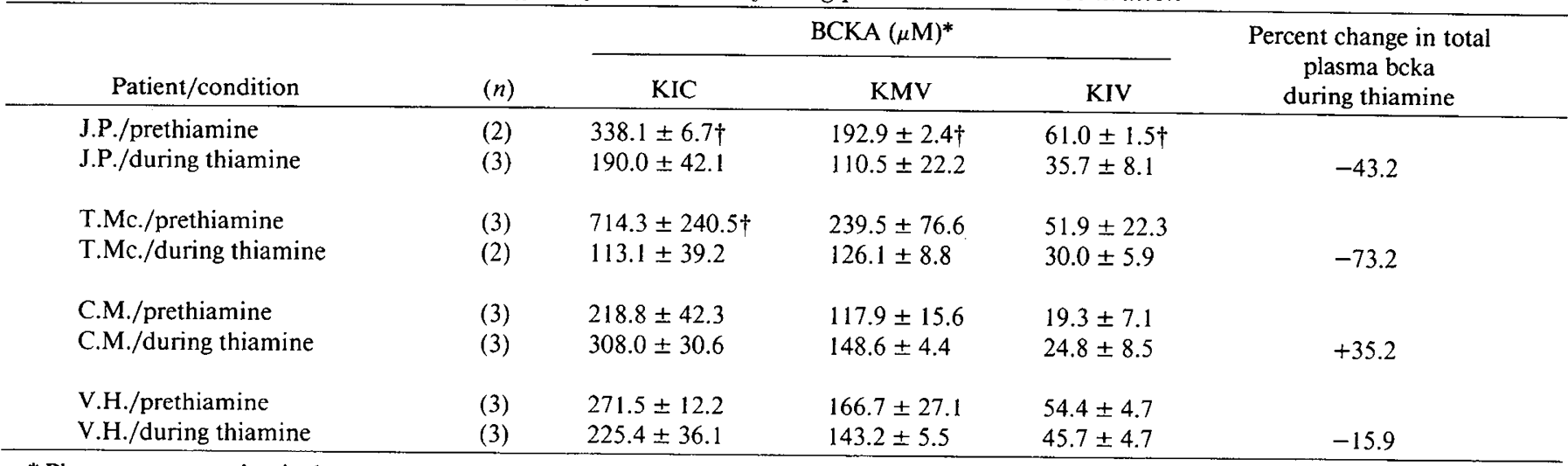

* Plasma concentration is the mean \pm 1 SD. When only two samples were available, concentration is the average and range.

$\dagger$ Plasma amino acid concentration was significantly less during thiamine therapy with $p<0.05$ using a one-tailed $t$ tested for independent mean probability.

lated from heparinized blood for enzyme assays. After baseline studies were completed, the children were given thiamine orally to continue daily at home with their usual diet for $3 \mathrm{wk}$. During the 4 th wk, while continuing thiamine, they were readmitted for fibroblast culture.

Quantitation of amino acids, organic acids, and renal tubular transport. Concentrations of amino acids were determined on protein-free filtrates of urine or plasma using lithium buffers in a Beckman $119 \mathrm{CL}$ amino acid analyzer. Organic acids were quantified using gas chromatography of their $O$-trimethylsilyl quinoxalinols (14). Urinary BCKA were determined by gas chromatography of either their methylesters using benzoic acid and $\left[1-{ }^{14} \mathrm{C}\right]$ pyruvate as an internal standard and recovery equivalent, respectively (15), or from their silylated oximes (14).

Renal filtration, excretion, and reabsorption of BCAA and
BCKA were calculated according to the formula (16):

$$
\begin{aligned}
& \text { 1. } F=G F R \times P \\
& \text { 2. } E=U \times V \\
& \text { 3. } T=F-E \\
& \text { 4. } \% T=100 \times T / F
\end{aligned}
$$

where $\mathrm{F}=$ filtered load in $\mu \mathrm{mol} / 24 \mathrm{~h}, \mathrm{GFR}=$ creatinine clearance $\mathrm{ml} / 24 \mathrm{~h}, \mathrm{P}=$ plasma concentration in $\mu \mathrm{mol} / \mathrm{ml}, \mathrm{E}=$ urinary excretion in $\mu \mathrm{mol} / 24 \mathrm{~h}, \mathrm{U}=$ urinary concentration in $\mu \mathrm{mol} / \mathrm{ml}$, $\mathrm{V}=$ urinary rate in $\mathrm{ml} / 24 \mathrm{~h}, \mathrm{~T}=$ net tubular reabsorption in $\mu \mathrm{mol} / 24 \mathrm{~h}$, and $\% \mathrm{~T}=$ percent reabsorption.

Isolation of mononuclear white cells and culture of skin fibroblast. Granulocyte-free, mononuclear, white blood cells were prepared from $10 \mathrm{ml}$ of heparinized blood using LSM solution (Litton Bionetics, Inc., Kensington, MD), a commercially ob- 
tained density gradient according to a modification of a previously described method $(7,8)$. BCKAD activity from the mononuclear cell fraction of each patient was compared with activity in cells from two controls.

Skin biopsies were obtained and cultured from explants in 75 $\mathrm{cm}^{2}$ plastic tissue culture flasks using Dulbecco-Vogt medium supplemented with $15 \%$ fetal bovine serum and $4 \mathrm{mM}$ glutamine. Cells from control and MSUD patients were matched for culture age. Monolayer cultures were harvested by treatment with $0.27 \%$ trypsin for $30 \mathrm{~min}$ at $37^{\circ} \mathrm{C}$.

Enzyme assays. Decarboxylation of $\left[1-{ }^{14} \mathrm{C}\right]$ labeled BCAA by mononuclear cells from peripheral blood and by intact cultured fibroblasts was performed using previously described methods (3). Mitochondrial inner membranes were isolated from fibroblasts ( 0.75 to $1.5 \mathrm{~g}$ wet weight) using Protease VI, homogenization, and differential centrifugation. Mitochondrial pellets were further treated with $0.5 \mu \mathrm{g}$ digitonin per ng mitochondrial protein and the inner membrane and matrix were isolated $(7$, 17). Branched-chain $\left[1-{ }^{14} \mathrm{C}\right] \alpha$-ketoacids were prepared as previously described (15). Enzyme activity was monitored by ${ }^{14} \mathrm{CO}_{2}$ released.

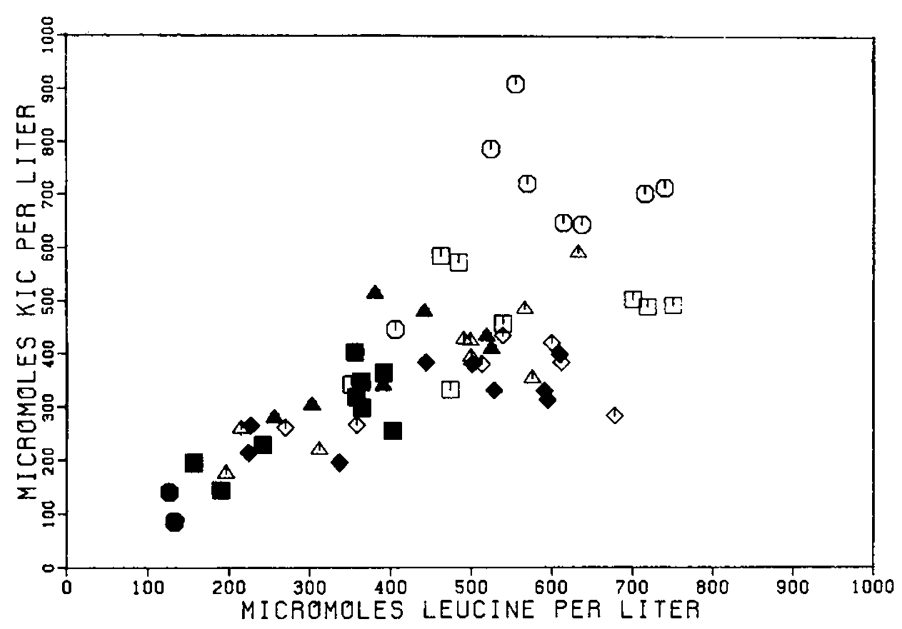

Fig. 1. Relationship between plasma leucine and KIC, effect of thiamine. Symbols represent patients in Table $1(0=\mathrm{TMc} ; \square=\mathrm{JP} ; \Delta=$ $\mathrm{CM} ; \diamond=\mathrm{VH})$. Open symbols were obtained before thiamine and closed symbols were obtained after $3 \mathrm{wk}$ of thiamine. The prethiamine values (open symbols) are seen predominantly in the higher concentrations.

\section{RESULTS}

Plasma concentrations of $B C A A$ and $B C K A$. Two children, J.P. and T.Mc., had significant $(p<0.05)$ decreases in plasma concentration of BCAA and BCKA during thiamine therapy (Tables 2 and 3). During thiamine administration, J.P.'s fasting plasma total BCAA decreased $51.7 \%$ and his BCKA decreased 43.2\%. T.Mc.'s fasting plasma BCAA concentration decreased $61.2 \%$ and her BCKA decreased $73.2 \%$. V.H. also improved. His plasma BCAA decreased $37.8 \%$ and his BCKA fell $15.9 \%$ during thiamine therapy. However, C.M. showed no improvement. Her BCAA rose $14.8 \%$ and her BCKA rose $35.2 \%$ during vitamin supplementation.

The relationship between plasma concentrations of leucine and $\mathrm{KIC}$ from all patients is illustrated in Figure 1. This relationship remained linear over these moderately elevated plasma values. The slope of their least square ratio is approximately one. Thus for any plasma leucine concentration less than $1.0 \mathrm{mM}$ a corresponding KIC concentration was found. The slopes of the least square ratios for KIV to valine and $\mathrm{KMV}$ to isoleucine were 0.25 and 0.7 , respectively.

Urinary excretion and renal transport of $B C A A$ and $B C K A$. The urinary excretion of BCAA and BCKA for $72 \mathrm{~h}$ under basal conditions and for $72 \mathrm{~h}$ during thiamine therapy are shown in Tables 4 and 5 .

J.P. excreted $39.3 \%$ less total BCAA and $56.1 \%$ less total BCKA during thiamine therapy. T.Mc. excreted $63.3 \%$ less BCAA and $91.7 \%$ less BCKA after taking thiamine. C.M. increased excretion of total BCAA by $24.4 \%$ but had essentially no change in total $\mathrm{BCKA}$ excretion during treatment with thiamine. Her increased excretion of BCAA reflected her elevated plasma concentrations of $\mathrm{BCAA}$ during her experimental period. Although V.H. excreted $43.3 \%$ more BCAA, his excretion of BCKA decreased by $19.8 \%$ during thiamine therapy.

The renal tubular transport of BCAA and BCKA was calculated before and during thiamine therapy. The rate of filtration for both amino and ketoacids were generally higher before thiamine and reflected the elevated plasma concentrations. However, the maximum tubular reabsorption capacities were not exceeded and more than $99 \%$ of all filtered BCAA and BCKA were reabsorbed during both study periods (Tables 6 and 7).

In vitro $B C K A D$ activity. The ability of freshly isolated mononuclear cells obtained before thiamine therapy to decarboxylate $\left[1-{ }^{14} \mathrm{C}\right]$ labeled leucine $(20 \mu \mathrm{M})$ is shown in Table 8 . Compared with control cells, those of J.P., T.Mc., and V.H. showed, respectively, $5.0,4.9$, and $15.7 \%$ activity. C.M.'s mononuclear cells had $0.8 \%$ of control activity.

BCKAD activity was assayed in whole cell and mitochondrial preparations obtained from cultured skin fibroblasts (Table 8).

Table 4. Effect of thiamine on 24-h urinary excretion of the BCAA

\begin{tabular}{|c|c|c|c|c|}
\hline \multirow[b]{2}{*}{ Patient } & \multicolumn{3}{|c|}{ BCAA $(\mu \mathrm{mol} / 24 \mathrm{~h} / \mathrm{g} \text { creatinine })^{*}$} & \multirow{2}{*}{$\begin{array}{c}\% \text { change in } \\
\text { total excretion of } \\
\text { BCAA during thiamine }\end{array}$} \\
\hline & Leucine & $\begin{array}{c}\text { Isoleucine } \\
\text { and alloisoleucine }\end{array}$ & Valine & \\
\hline J.P./prethiamine & $121.6 \pm 6.2 \dagger$ & $43.1 \pm 5.3 \dagger$ & $164.5 \pm 29.7 \dagger$ & \\
\hline J.P./during thiamine & $76.2 \pm 18.2$ & $22.6 \pm 6.3$ & $101.1 \pm 7.3$ & -39.3 \\
\hline T.Mc./prethiamine & $232.6 \pm 8.9 \dagger$ & $39.3 \pm 24.0$ & $75.9 \pm 50.5$ & \\
\hline T.Mc./during thiamine & $39.1 \pm 11.6$ & $29.8 \pm 19.2$ & $58.6 \pm 25.6$ & -63.3 \\
\hline C.M./prethiamine & $232.7 \pm 18.2 \dagger$ & $38.6 \pm 2.0 \dagger$ & $102.6 \pm 2.2$ & \\
\hline C.M./during thiamine & $311.6 \pm 26.6$ & $44.6 \pm 0.2$ & $108.8 \pm 18.2$ & +24.4 \\
\hline V.H./prethiamine & $124.7 \pm 12.3$ & $35.5 \pm 11.3 \dagger$ & $70.6 \pm 22.3$ & \\
\hline V.H./during thiamine & $149.3 \pm 52.8$ & $80.9 \pm 13.0$ & $100.6 \pm 36.1$ & +43.3 \\
\hline
\end{tabular}

* Concentration of aminoacid is the mean \pm 1 SD of three separate 24-h urine collections.

† Urinary concentration of amino acid was significantly less during thiamine therapy with $p<0.05$ using a one-tailed test $t$ test for independent mean probability. 
Table 5. Effect of thiamine on 24-h urinary excretion of the BCKA

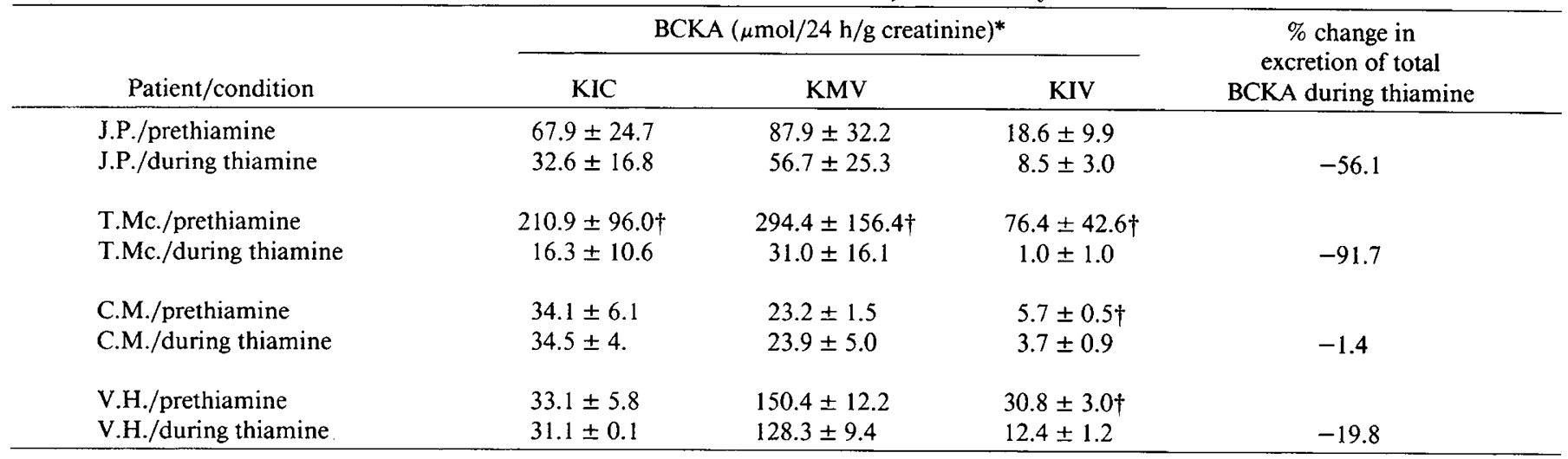

* Concentration of $\alpha$-ketoacid is the mean $\pm 1 \mathrm{SD}$ of three separate 24 -h urine collections.

$\dagger$ Urinary concentration of $\alpha$-ketoacid was significantly less during thiamine therapy with $p<0.05$ using a one-tailed $t$ test for independent mean probability.

Table 6. Rates of BCAA filtration $\left(F_{A A}\right)$, excretion $\left(E_{A A}\right)$, and net tubular reabsorption $\left(T_{A A}\right)$ expressed in $\mu$ mol of amino acid/24 $h$ and $\%$ of filtered amino acid reabsorbed $\left(\% T_{A A}\right)$ before and during thiamine therapy*

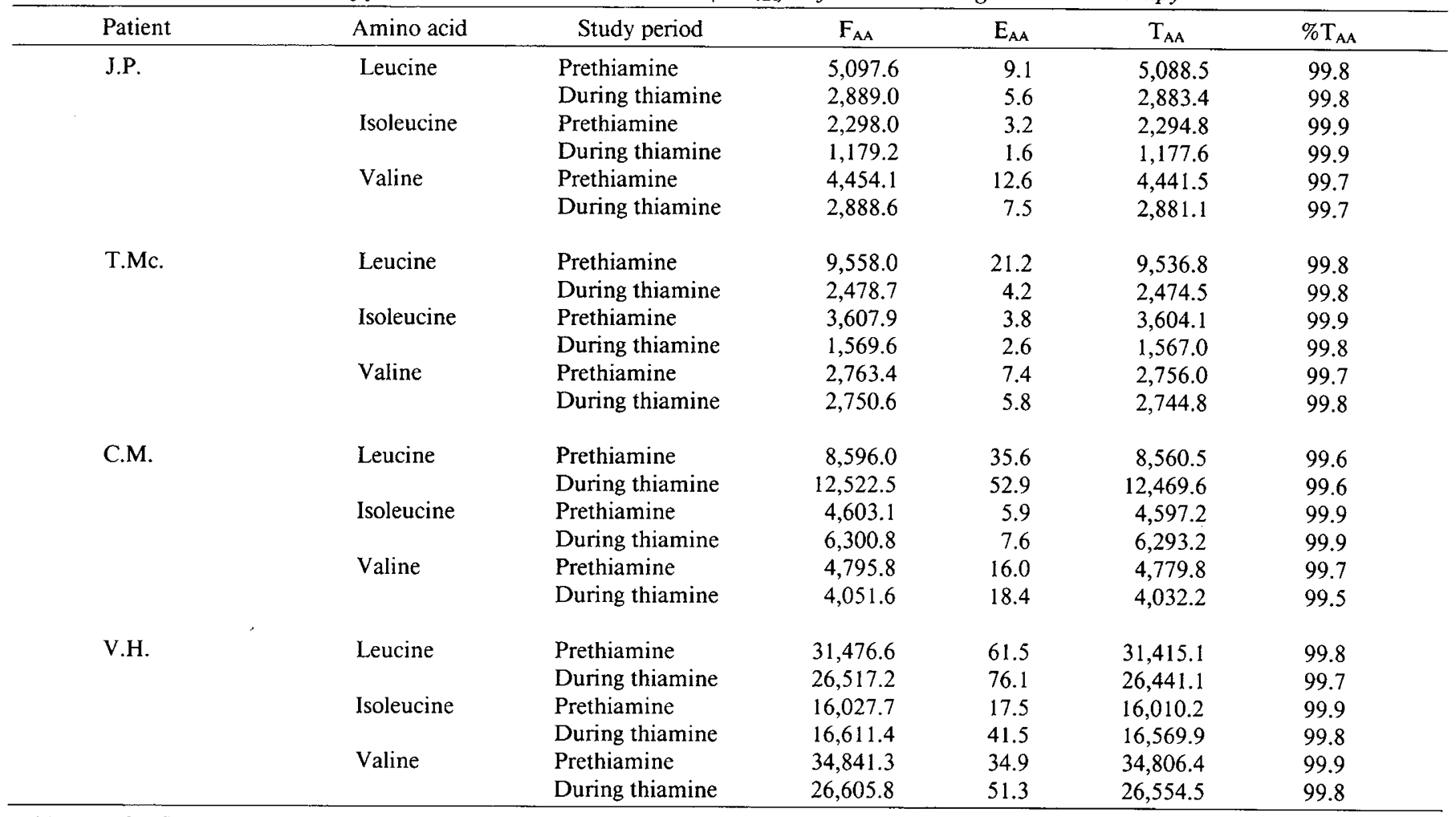

* Values for filtration and excretion were derived from the mean plasma and urinary concentrations of BCAA from two or three collections during each study period. Calculations are described in "Results."

Except for V.H. there was close agreement between the enzyme activity in freshly prepared mononuclear cells and fibrobasts grown in vitro.

\section{DISCUSSION}

Since responsivity to thiamine may not correlate with the clinical course, we sought to determine how to predict which patients with MSUD would respond to thiamine therapy. Three of four children in this study responded after $4 \mathrm{wk}$ of thiamine, as demonstrated by improved biochemical status.

Three of these four patients were classified as having classical disease because of their presentation in infancy and recurrent episodes of ketoacidosis (18). Two of these children, J.P. and T.Mc., had a significant decrease in their fasting plasma concen- trations and their $24 \mathrm{~h}$ urinary excretion of total BCAA and BCKA during thiamine treatment. V.H. who was classified as having an intermediate form, i.e. developmental delay without bouts of symptomatic ketoacidosis, also had a biochemical response to thiamine. His response might have been blunted as he probably had residual effects of his previous $7 \mathrm{yr}$ of thiamine treatment.

Each patient's response to thiamine correlated with the enzyme activity in their peripheral blood monocytes. The three patients with residual enzyme activity of approximately $5 \%$ or more, showed an in vivo response to thiamine. C.M. with less than $1 \%$ activity in her white cells, did not respond. She subsequently died during an episode of severe ketoacidosis.

The higher enzyme activity in V.H.'s freshly isolated peripheral blood mononuclear cells as compared to that in his skin fibro- 
Table 7. Rates of BCKA filtration $\left(F_{K A}\right)$, excretion $\left(E_{K A}\right)$, and net tubular reabsorption $\left(T_{K A}\right)$ expressed in $\mu$ moles of $\alpha$-ketoacid/24 $h$ and $\%$ of filtered $\alpha$-ketoacid reabsorbed $\left(\% T_{K A}\right)$ before and during thiamine therapy*

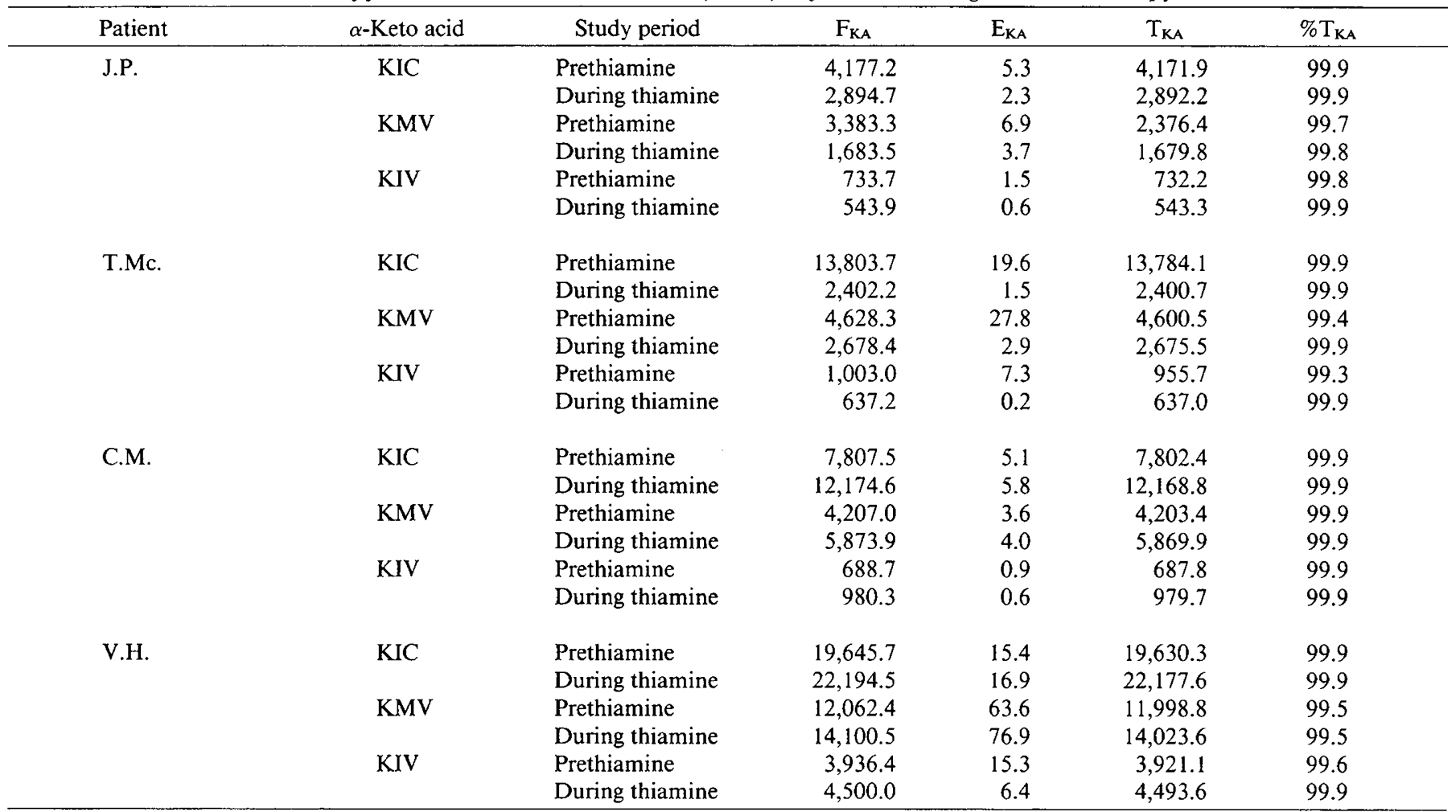

* Values for filtration and excretion were derived from the mean plasma and urinary concentration of BCKA from two or three collections during each study period. Calculations are described in "Results."

Table 8. Activity of BCKAD as measured in mononuclear peripheral blood cells and cultured skin fibroblasts*

\begin{tabular}{|c|c|c|c|}
\hline \multirow[b]{3}{*}{ Patient } & \multicolumn{3}{|c|}{$\begin{array}{l}\text { Enzyme activity expressed as mean \% control } \\
\text { activity }\end{array}$} \\
\hline & \multirow{2}{*}{$\begin{array}{l}\text { Peripheral blood } \\
\text { mononuclear cells } \dagger\end{array}$} & \multicolumn{2}{|c|}{ Cultured Skin Fibroblasts } \\
\hline & & Whole cell $\neq$ & Mitochondria§ \\
\hline J.P. & 5.0 & 9.4 & 7.5 \\
\hline T.Mc. & 4.9 & 2.7 & 2.6 \\
\hline C.M. & 0.8 & 0.5 & 0.6 \\
\hline V.H. & 15.7 & 5.5 & 6.0 \\
\hline
\end{tabular}

* \% activity derived from mean of triplicate observations.

$\dagger 1-\left[{ }^{14} \mathrm{C}\right]$ leucine $20 \mu \mathrm{M}$ as substrate.

$\ddagger 1-\left[{ }^{14} \mathrm{C}\right]$ leucine $20 \mu \mathrm{M}$ as substrate. Control activity $=2.56 \mathrm{pmol}$ ${ }^{14} \mathrm{CO}_{2}$ released/min/mg protein.

$\S 1-\left[{ }^{14} \mathrm{C}\right] \mathrm{KIC} 0.1 \mu \mathrm{M}$ as substrate. Control activity $=45 \mathrm{pmol}{ }^{14} \mathrm{CO}_{2}$ released $/ \mathrm{min} / \mathrm{mg}$ protein.

blasts may have also reflected his previous thiamine therapy. Unlike the mononuclear cell and whole cell fibroblast assay, the mitochondrial assays required addition of all soluble cofactors and contained saturating amounts of thiamine pyrophosphate. This assay may more accurately define the maximal activity of normal and mutant enzymes, but does not define the functional activity in the intact cell.

While we, as have others (19), found a linear correlation between plasma concentrations of each BCAA and its ketoacid analogue, an unexpected finding was the efficient renal tubular reabsorption of BCAA and BCKA within these physiologic conditions. Reflecting elevated plasma concentrations, the rates of filtration of BCAA and BCKA were higher before thiamine therapy. However, all BCAA and BCKA were maximally reabsorbed in all children during both study periods. Thus the reduced plasma concentrations of $\mathrm{BCAA}$ and $\mathrm{BCKA}$ in three responders did not result from increased urinary excretion. These observations differ from Lancaster, et al. (20) who found a higher ratio of $\mathrm{BCKA}$ to $\mathrm{BCAA}$ in the urine compared to that in the blood, and concluded that the BCKA were preferentially excreted by urinary tubular secretion. There are at least two possible explanations for these different observations. Lancaster et al. (20) made their observations in one newborn female. Her serum concentrations of BCKA were five to 10 times greater than in our patients. Additionally, renal transport of amino acids in older children is more efficient than in a newborn infant (21). If both BCAA and BCKA are maximally reabsorbed, an additional treatment of the acute ketoacidosis of MSUD would be to enhance excretion of BCKA.

Several mechanisms could explain thiamine responsivity. We proposed one such model $(7,8,11,12)$. By increasing thiamine intake, intracellular concentrations of thiamine pyrophosphate increase and saturate binding sites on the decarboxylase moiety of the BCKAD complex. The complex undergoes a conformational change, rendering it more resistant to biologic degradation and thus increasing its total activity by prolonging its biologic half-life. Assuming that patients with MSUD have normal mechanisms for absorption of thiamine, and conversion to thiamine pyrophosphate, the differences in clinical responsivity reflect the ability of thiamine pyrophosphate to bind and stabilize the mutant complex.

Chuang et al. (22) have proposed an alternate model by finding a thiamine pyrophosphate mediated increase in affinity of $\mathrm{BCKAD}$ for the BCKA in cells cultured from a patient originally described by Scriver et al. (6). The data from this current study are compatible with either model. If thiamine pyrophosphate saturation produced stabilization or increased affinity of a mutant enzyme complex to BCKA then those mutations with at least a critical amount of residual activity would most likely respond with an increase in the level of enzyme activity. Such a response to excess thiamine would not be expected if there were 
a major conformational change in the protein, or if the protein were absent because of a regulatory mutation. Further explanations for vitamin responsivity await in vitro confirmation by complementation studies of various cell lines with mutant BCKAD, and better resolution at the molecular level.

With increased newborn screening for MSUD and other metabolic disorders we must define clinical and biochemical criteria for responsivity to dietary and vitamin therapies. Control studies are rarely performed on the newly diagnosed neonate. Therefore, experiences gained from the study of older children must be used in the neonate. Based on our experiences with these and other patients, we believe that after the diagnosis of MSUD has been established, all infants should be started on thiamine (10 to 20 $\mathrm{mg} / \mathrm{kg} /$ day) and a diet restricted in BCAA. A biochemical response to thiamine may require 3 to 4 wk.

Acknowledgments. The authors thank Dr. Milan Blacovics for referring J.P. and Dr. Phyllis Acosta who supervised the dietary management.

\section{REFERENCES}

1. Menkes JH, Hurst PL, Craig JM 1954 A new syndrome: progressive familial infantile cerebral dysfunction associated with an unusual urinary substance. Pediatrics 14:462-466

2. Dancis J, Jansen V, Hutzler J, Levitz M 1963. The metabolism of leucine in tissue culture of skin fibroblasts of maple syrup disease. Biochem Acta 77:532-534

3. Elsas LJ, Pask BA, Wheeler FB, Perl D, Trusler S 1972. Classical maple syrup urine disease: cofactor resistance. Metabolism 12:929-944

4. Westall RG 1963 Dietary treatment of maple syrup urine disease. Am J Dis Childhood 113:58-59

5. Synderman SE, Norton PM, Roitman E, Holt EL 1964 Maple syrup urine disease with particular reference to dietary therapy. Pediatrics $34: 434-472$

6. Scriver CR, Clow CL, MacKenzie S, Devlin T 1971 Thiamine responsive maple syrup urine disease. Lancet 1:310-312

7. Danner DJ, Wheeler FB, Lemmon SK. Elsas LJ 1978 In vivo and in vitro response of human branched chain alpha-ketoacid dehydrogenase to thiamine and thiamine pyrophosphate. Pediatr Res 12:235-238

8. Elsas LJ, Danner DJ, Rogers BL 1976 Effect of thiamine on normal and mutant human branched chain alpha-ketoacid dehydrogenase. In: Gubler C, Fujiwara M, Dreyfus P, (eds) Thiamine. John Wiley and Sons, Inc., New York, pp 335-352

9. Duran M, Tielens AGM, Wadman SK, Stigter JCM, Kleijer WJ 1978 Effects of thiamine in a patient with a variant form of branched chain ketoaciduria. Acta Paediatr Scand 67:367-376

10. Pueschel SM, Bresnan MJ, Shih VE, Levy HL 1979 Thiamine-responsive intermittent branched chain ketoaciduria. J Pediatr 22:628-631

11. Danner DJ, Davidson ED, Elsas LJ 1975 Thiamine increases the specific activity of human liver branched chain alpha-ketoacid dehydrogenase. Nature 254:529-530

12. Danner DJ, Lemmon SK, Elsas LJ 1980 Stabilization of mammalian liver branched chain alpha-ketoacid dehydrogenase by thiamine pyrophosphate. Arch Biochem 202:23-28

13. Elsas LJ, Danner, DJ 1982 The role of thiamine in maple syrup urine disease. Ann NY Acad Sci 378:404-421

14. Schwarz HP, Karl IE, Bier DM 1980 The $\alpha$-keto acids of branched-chain amino acids: simplified derivation for physiological samples and complete separation as quinoxalinols by packed column gas chromatography. Anal Biol 108:360-366

15. Elsas LJ, Priest JH, Wheeler FB, Danner DJ, Pask BA 1974 Maple syrup urine disease: Coenzyme function and prenatal monitoring. Metabolism 23:569579

16. Elsas LJ, Rosenberg LE 1979 Renal glycosuria. In: Early LE, Gottschalk, CW (eds) Strauss and Welts Diseases of the Kidney, 3rd ed, Vol 2. Little, Brown and Company, Boston, pp 1021-1028

17. Danner DJ, LJ Elsas 1975 Subcellular distribution and cofactor function of human branched chain alpha-ketoacid dehydrogenase in normal and mutant cultured fribroblasts. Biochem Med 13:7-22

18. Tanaka K, Rosenberg LE 1983 Disorders of branched chain aminoacid and organic acid metabolism. In: Stanbury JB, Wyngaarden JB, Fredrickson DS, Goldstein JL, Brown MJ (eds) The Metabolic Basis of Inherited Disease. McGraw-Hill Book Company, New York, pp 440-473

19. Synderman SE, Goldstein F, Sansaricq C, Norton PM 1984 The relationship between the branched chain amino acids and their alpha ketoacids in maple syrup urine disease. Pediatr Res 18:851-853

20. Lancaster G, Mamer OA, Scriver CR 1974 Branched chain alpha-ketoacids isolated as oxamine derivatives: relationship to the corresponding hydroxyacids and aminoacids in maple syrup urine disease. Metabolism 23:257-265

21. Brodehl J, Gellissen K 1968 The renal transport of free aminoacids in infancy and childhood. Pediatrics 42:395-404

22. Chuang DT, Ku LS, Cox RP 1982 Thiamine-responsive maple syrup urine disease: decreased affinity of the mutant branched chain alpha-ketoacid dehydrogenase for alpha-ketoisovalerate and thiamine pyrophosphate. Proc Natl Acad Sci USA 79:3300-3304 